\title{
Social Learning with Mobile Devices in Preschool Classrooms
}

\author{
Rachel Ralph ${ }^{1 *}$, Stephen Petrina ${ }^{1}$ \\ ${ }^{1}$ University of British Columbia, 224-1844 7th Ave West, V6J1S8 Vancouver, CANADA \\ *Corresponding Author: rachel.ralph@alumni.ubc.ca \\ Citation: Ralph, R. and Petrina, S. (2018). Social Learning with Mobile Devices in Preschool Classrooms. \\ European Journal of STEM Education, 3(3), 12. https:/ / doi.org/10.20897/ ejsteme/3872
}

Published: September 6, 2018

\begin{abstract}
How do prosocial sharing behaviours of preschool-aged children progress or diminish when interacting with mobile devices? Participants include five children (ages 3-4) within a preschool setting in Vancouver, British Columbia. Design-based research and video ethnography were used for qualitative and quantitative data collection and analysis. Data collection included two researcher cameras for participant observation as well as multiple personal point of view cameras (Snapcam Ion) worn by participants. To record observations of sharing, the Observational Measure of Prosocial Incidents (OMPI) was used. Procedures included a teaching intervention for data collection and analysis: 1) Reading Mine, a digital story, 2) Demonstration of Chatterpix Kid, and 3) Limited iPad-to-children ratio using Chatterpix Kid to animate pictures taken. Nuanced in various ways, results indicate a higher frequency of incidents of prosocial behaviours compared to nonsocial or antisocial behaviours when interacting with mobile devices. The research underscores the importance of investigating children's uses of mobile devices and the utility of point of view wearable cameras.
\end{abstract}

Keywords: preschool-aged children, prosocial behaviours, science and technology education, mobile devices, cameras

\section{INTRODUCTION}

Challenges of prosocial behaviour are pervasive across STEM education. This article addresses children's (ages 3-4) prosocial behaviour with iPads in a preschool setting. With a focus on technology, mobile or tablet devices, such as iPads, and smartphones are increasingly used in a variety of settings. A number of researchers associate negative effects resulting from over-exposure to technologies, such as attention deficits, cyberbullying, physical inactivity, and selfishness (Adams and Thompson, 2016; Clayton et al., 2013; Papadakis et al., 2018; Rosen et al., 2013). While, media and technology (M\&T) have been associated with negative effects, there is also ample evidence of positive outcomes. These include: deeper or higher level learning, increased motivation, more independent work, and increased confidence and curiosity (Bullock et al., 2017; Flewitt et al., 2014; Herodotou, 2018; Lynch and Redpath, 2014; Zhou and Yadav, 2017). As we move into the third decade of the 21 st century, with M\&T ubiquitous in early childhood education (ECE), it is especially important to empirically investigate children's interactions with devices. Relatively few studies have explored the impacts of STEM, and in particular of technology, on young children between the ages 2-5. Although some research has been conducted analyzing how young children share technology (Medvin et al., 2000; Muller and Perlmutter, 1984), for the most part this research focuses on computers, prior to the prevalence of mobile devices. Mobile devices can impact learning at various times and spaces (Chang et al., 2018). Technology, mobile or tablet devices, such as iPads, and smartphones are increasingly used in diverse settings. In the UK, children, at an average of eight years old, use the internet and have their own smartphones or tablets (Mascheroni and Ólafsson, 2014). Children understand how to "watch videos" 
and "play games" (Dashti and Yateem, 2018, p. 128; Mascheroni and Ólafsson, 2014, p. 16). The emergence of prosocial behaviours can be positively or negatively shaped by the introduction of technology (De Simone, 2013; Edwards and Pye, 2011; Luzón, 2011); however, it is unclear how prosocial sharing behaviours of young children are reinforced or suppressed through the use of devices, such as iPads.

This empirical case study explored how preschool-aged children interact and share with each other while using iPads. In particular, how do prosocial sharing behaviours of preschool-aged children progress or diminish when interacting with mobile devices?

\section{BACKGROUND: SOCIAL LEARNING THEORY}

Social learning theory addresses a series of social processes through which we learn and learn how to act (Bandura, 1977). In particular, it addresses learning by observing another person's behaviours and the consequences of that behaviour. For example, a younger sibling may observe that the consequence that happens when their older sibling does not do their chores is to have their video game taken away. People are able to control their own behaviour, but that behaviour is often influenced by environmental factors. Self-regulatory capacities are generated from cognitive supports and consequences for one's own actions (Bandura, 1977). Self-regulation is the "self-directive process by which learners transform their mental abilities into academic skills" (Zimmerman, 2002, p. 65). In other words, self-regulation means being self-aware, intrinsically motivated, and having the skill to apply knowledge appropriately. For example, early in education children are taught to walk and not run in the hallways at school and at some point, most children are able to regulate themselves without reminders from their teachers to walk not run.

Overall, social learning theory suggests that learned behaviour from an authority figure or cultural norms dictates behaviour (Berkowitz, 2004; Eisenberg, 1982). In other words, when we behave a certain way, for example sharing a cookie, we aren't doing this because we have learned about sharing; rather we share because that is what the teachers or parents expect us to do. According to Bierhoff (2002), socially approved behavioural modeling is strongly linked to prosocial behaviour because "[behavioural] models frequently function as releasers that contribute to the performance of prosocial behaviour in children" (p. 74). Children may have learned a behaviour previously but now rely on modeling or cues to facilitate behaviours. The next section explains in more detail the manifestations of prosocial behaviours with preschool-aged children.

\section{Preschool Children's Prosocial Sharing Behaviours}

Prosocial behaviours are defined as one person or persons acting to benefit another or others. Children's prosocial behaviours include: sharing, comforting, helping, and cooperating; and generally, emerge in preschool years (ages 2-5) (Belacchi and Farina, 2012; Eisenberg et al., 2014; Radke-Yarrow et al., 1976). Researchers have noted that parents and teachers prompt children to share by the age of two (i.e., food, toys, etc.) (Brownell et al., 2013; Chernyak and Kushnir, 2013; Dunfield, 2014; Paulus et al., 2013). Young children readily share physical objects, such as toys or stickers (Hay et al., 1999; Paulus et al., 2013) and can self-initiate sharing with computers (Medvin et al., 2000; Muller and Perlmutter, 1984). However, it is unclear how prosocial sharing behaviours of young children are reinforced or suppressed through the use of mobile devices, such as iPads.

Children exhibit a variety of behaviours at a very young age by mimicking adults' (e.g., their parents) actions, or language and watching every move that everyone makes around them (Bandura, 1977; Dashti and Yateem, 2018; Plowman et al., 2008). These early behaviours are positive and negative. They could be learning please and thank you. They could be learning how to pick their nose. They could be learning how to say hello or goodbye or learning curse words. Learned behaviours are based upon the social situation in which they are immersed. In many social situations, whether at home, interacting with television and videos on devices, or at school, children are learning both prosocial and antisocial and aggressive behaviours.

Early in life, reciprocity occurs between parents and children that supports early socialization skills (Feldman et al., 2013). In particular, Feldman et al. (2013) studied 86 families observing mother-child and father-child reciprocal behaviours. They found that children who had experienced mother-child or father-child reciprocity demonstrated lower aggression and higher social competence in social situations at school. As infants become toddlers, sharing reciprocity transfers from parents to the inclusion of peers. Children are more likely to share with their friends as they progress throughout ECE (Paulus and Moore, 2014; Warneken and Tomasello, 2013). Moreover, friendship and reciprocity are affiliated with the balance of social contracts in which children expect a reciprocal friendship (Fujisawa et al., 2008).

As children enter preschool and ECE classrooms, their exposure to social situations expands. Essential to cognitive development, socialization skills or lack of can create a division amongst children (Brownell et al., 2013; Dunfield, 2014; Eisenberg-Berg, 1981; Vygotsky, 1978). Children who exhibit prosocial behaviours may not want to affiliate with antisocial or aggressive children and often form friendships based on peer affiliations (Dahl et al., 
Table 1. DBR characteristics definitions and usage in research study

\begin{tabular}{|c|c|}
\hline DBR Characteristic & How it was used in our research \\
\hline Interventionist & $\begin{array}{l}\text { This approach introduces an innovative intervention design or A designed teaching intervention was created } \\
\text { practice to disrupt current education practices (Anderson and using iPads to encourage sharing behaviours } \\
\text { Shattuck, 2012) } \\
\text { through designed sharing scenarios. }\end{array}$ \\
\hline Pragmatic & $\begin{array}{l}\text { This approach allows researchers to connect theory to practice Based on social learning theory, a designed } \\
\text { (Reimann, 2011; Wang and Hannafin, 2005) } \\
\text { intervention connected the theories to } \\
\text { practice in ECE classrooms. }\end{array}$ \\
\hline $\begin{array}{l}\text { Collaborative } \\
\text { between researchers } \\
\text { and practitioners }\end{array}$ & $\begin{array}{l}\text { This allows researchers and teachers to co-construct the An early pilot stage was designed and tested } \\
\text { intervention by identifying the problem and designing the solution with teachers. }{ }^{1} \\
\text { (Dede, 2005; Jacobson, 2014; Wang and Hannafin, 2005) }\end{array}$ \\
\hline Iterative and flexible & $\begin{array}{l}\text { There are multiple iterations or phases that are flexible as they may Each phase allowed for analysis and feedback } \\
\text { change throughout the study based on analysis and feedback from from the researcher, as well as the } \\
\text { the researchers and participants (Anderson and Shattuck, 2012; participants. Iterations allowed for analysis } \\
\begin{array}{ll}\text { Design-Based Research Collective, 2003; Jacobson, 2014). } & \text { and refinement until a 'successful' } \\
\text { intervention was developed. }\end{array}\end{array}$ \\
\hline Integrative & $\begin{array}{l}\text { This method employs a multi-methodological approach that Data were collected iteratively to allow for } \\
\text { collects data through multiple methods that is both formative and formative assessment, which influenced the } \\
\text { summative (Barab and Squire, 2004; Edelson, 2002). }\end{array}$ \\
\hline $\begin{array}{l}\text { Situated in authentic } \\
\text { 'real-world' settings }\end{array}$ & $\begin{array}{l}\text { This method captures data outside of traditional laboratory settings, Data were captured in authentic ECE } \\
\text { in authentic classrooms or in situ settings (Brown, 1992). Authentic classrooms. The two sites that were visited } \\
\text { 'real-world' settings can be single classrooms, multiple classrooms were the children's ECE classroom that they } \\
\text { at a school, or even multiple classrooms across a district or districts. attended every day or every other day. }{ }^{1}\end{array}$ \\
\hline
\end{tabular}

2013; Eivers et al., 2012; Fabes et al., 2012; Fujisawa et al., 2008; Liao et al., 2014). In other words, children will share toys with other children who also share toys. Children who display antisocial behaviours often affiliate or play with other peers who also display antisocial behaviours. Peers who are aggressive tend to associate with other children who are also aggressive (Eivers et al., 2012; Persson, 2005).

This section explored prosocial sharing behaviours of preschool aged children in ECE classrooms. The next section will describe the methodologies used for this research.

\section{METHODOLOGIES}

Design-based research (DBR) and video ethnography were used for qualitative and quantitative data collection and analysis. DBR was initially developed to refine innovations and create iterative methodologies that link theory to practice (Brown, 1992; Collins et al., 2004). The paradigm has evolved into a methodology for studying innovative learning environments, which often include technologies, in authentic, real-world classroom settings (Sandoval and Bell, 2004). The characteristics of DBR are essential to its use (Table 1).

Video ethnography was initially developed to record naturalistic experiences and habits that can be analyzed and re-analyzed (Heath et al., 2010). With the advent of M\&T, the concept of space has been transformed from a physical space to an online virtual space. Hammersley and Atkinson (2007) suggest that "ethnographies of digital life itself are important aspects of contemporary social research" (p. 137) and many ethnographers attempt to employ the use of audio and video technologies to support data collection (Creswell, 2013; Erickson, 2011; Erickson and Wilson, 1982; Fetterman, 1989). Video recording devices have become relatively inexpensive and allow researchers to record in 'natural' settings, such as classrooms (Heath et al., 2010). The examination of digital spaces can include: virtual classrooms, social networks, various websites, and blended learning environments. When conducting research with preschool-aged children, video recordings of the ECE classroom should be a part of data collection to understand, explore, and research digital aspects of education. The use of video in qualitative research allows an ethnographer to enhance their study because video recordings have an increased capacity for analysis and manipulation of data, and it is possible to reanalyze footage even after work has been published (Hayashi and Tobin, 2012; Pearce et al., 2010). Using video recordings and manipulating digital data demand "new capabilities and knowledge" that early ethnographies didn't allow (Adams and Thompson, 2016, p. 114). Video enables a "fine-grained scrutiny of moments of social life" (Heath et al., 2010, p. 3), which could be quite limited in a researcher's hand-written notebook in the chaotic setting of the ECE classroom. In the current study, the audio portion of the data was quite difficult to understand because many of the participant's voices had a similar tone, and several had speech difficulties. The video recording assisted in analysis by enabling views of the children's mouth and vocal gestures; transcribing and analyzing footage facilitated an understanding of what was said.

This section described, DBR and video ethnography, the two methodologies used in this research. The next section explains the methods used, including data collection, the participants and ethical considerations, and data analysis. 


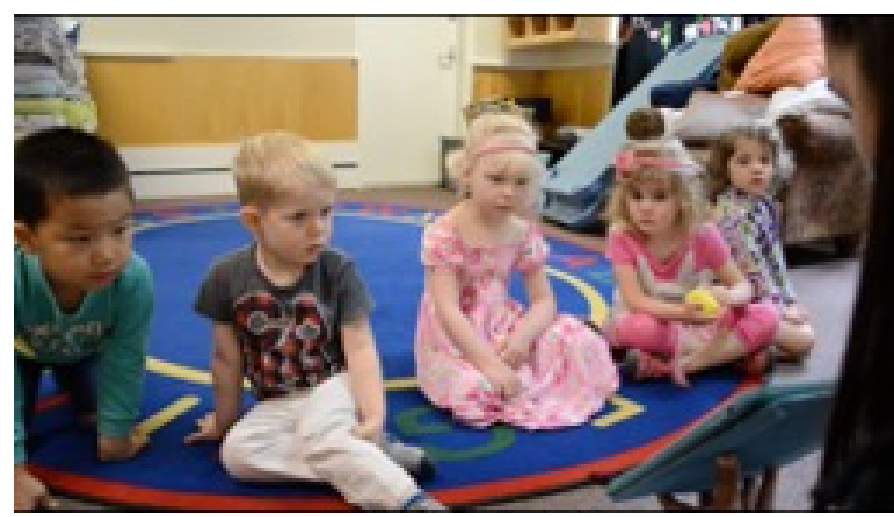

Figure 1. Participants reading an iPad story with the researcher.

\section{Methods and Data Collection}

The study included two researcher cameras for participant observation as well as multiple personal point of view cameras (Snapcam Ion) worn by participants. Field notes, semi-structured interviews, open focus-group discussions, and artifacts from children's drawings and animations on the iPads using the Chatterpix Kid app were also collected. Chatterpix Kid app was chosen based on the four pillar model of Hirsh-Pasek et al. (2015) and reflective of the rubric from Papadakis et al. (2017) (Ralph, 2017a).

This article reports one scenario, based on the most successful parts of an intervention developed in a prior phase of a larger study (Ralph, 2017b). The scenario had three activities: reading the digital story, Mine, researcher demonstration of Chatterpix Kid, and limited iPad-to-children ratio using Chatterpix Kid to animate pictures taken. In the first activity, the first author read Mine, a digital picture book. Participants were asked simple questions (i.e., is this good or bad? OR do you know what an iPad is?) to prompt discussion during the reading. The scenario helped facilitate the interview process and a semi-structured interview was conducted after the story was completed. The children then used the Chatterpix Kid app for animating pictures they took. First the app was demonstrated to the children. Once there was a basic understanding of the app, the participants worked with each other to take pictures around the room and animate a mouth within the app to talk. Participants worked independently and in groups of two and three. This scenario ended with children watching their animations.

\section{Participants}

Participants were preschool children $(\mathrm{n}=5)$ who attended the full day of a 12-month registered ECE preschool program (Figure 1). There were three girls and two boys. Convenience sampling was used. Located in Vancouver, British Columbia the preschool accommodates a range of families with diverse ethnic backgrounds and socioeconomic means.

\section{Ethical Considerations When Working with Children}

When working with children, it is imperative to consider ethical concerns. Researchers in Canada, as guided by the Tri-Council Policy Statement (TCPS) and university research ethics boards, abide to a code of ethical standards. The ethical standards include: attention to privacy, awareness of potential exploitation, acquiring consent, avoiding deception, and understanding the impact of costs to benefits of research (Dockett et al., 2009; Fetterman, 1989; Graham et al., 2013; Hammersley and Atkinson, 2007; Hunleth, 2011; Musante, 2014). The code of ethical standards applies to all human subjects and each standard must be addressed when working with young children, including: consent and assent, privacy, avoiding deception, and being conscious of potential risks and exploitation. The children were underage; therefore, consent and image/video release forms were signed by their parent(s) or guardian(s). Also, verbal and visual checks were used throughout the study to confirm the child's assent.

\section{Data Analysis}

Qualitative and quantitative data analyses were used. NVivo software was used for the qualitative analysis of video data (QSR International, 2016). To record observations of sharing, the Observational Measure of Prosocial Incidents (OMPI) was used (Ramaswamy and Bergin, 2009). The social behaviours of the children were initially divided into the following categories: offering, showing, allowing another child to use an object, and turn taking (Ramaswamy and Bergin, 2009). Multiple levels of coding were analyzed using NVivo software (QSR International, 2016). The initial four codes were insufficient because they did not address non-sharing behaviours repeated by the children across the activities. Nonsocial behaviours were observed when the children worked independently. Antisocial behaviours were observed when the children behaved in ways that opposed sharing behaviours, such as pushing another child away or saying no. Nonsocial was established as different from antisocial. Typically, 
Table 2. Codes and subcodes for children using iPads

\begin{tabular}{ll}
\hline Event code & Event subcode \\
\hline Nonsocial behaviour & Work independently \\
\hline Antisocial behaviour & Pull item away \\
\hline Prosocial individual behaviour & $\frac{\text { Allowing use }}{\text { Offering }}$ \\
\hline Prosocial group behaviour & Showing \\
\hline & Taking turns \\
\hline & Watch together, researcher controls \\
\hline & Multiple hands holding device \\
\hline & Touch screen together \\
\hline
\end{tabular}
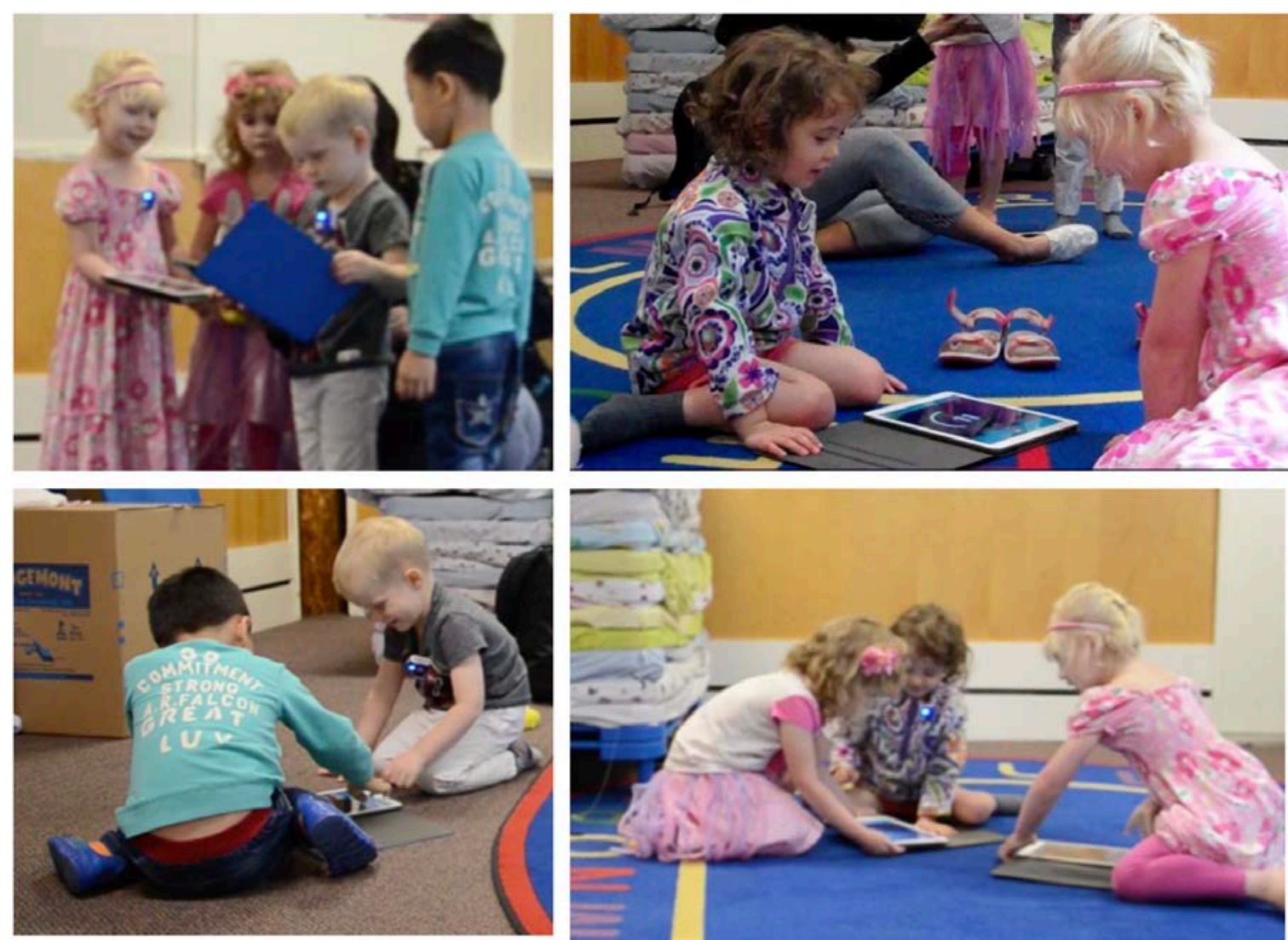

Figure 2. Participants sharing iPads

antisocial behaviours have a negative connotation and sometimes the children would work alone, not to be antisocial or isolated, but rather to work independently. Prosocial behaviours included all of the positive sharing events in which the children would share. For finer grained qualitative data analysis, these three main event codes were divided into subcodes (Table 2).

For the quantitative results, SPSS software was used (IBM Corp, 2016) to analyze prosocial, antisocial, and nonsocial behaviours. The data were measured based on statistical frequencies and Cohen's Kappa agreement for inter-rater reliability. Qualitative and quantitative data were triangulated.

Cohen's Kappa was calculated to determine inter-rater reliability through a second coder who coded $10 \%$ of a random set of events. Cohen's Kappa represents moderate agreement value at .5, good agreement value at .7, and very good agreement above .8 (Pallant, 2010). Values of Cohen's Kappa indicated very good agreement for nonsocial behaviours (Cohen's Kappa $=.85, p<.0005)$, moderate agreement for antisocial behaviours (Cohen's Kappa $=.55, p<.0005$ ), and very good agreement for prosocial behaviours (Cohen's Kappa $=.82, p<.0005$ ).

This section described the methods and procedures of this study. It addressed video data collection, ethics approval, and qualitative and quantitative data analysis. The next section explains the results of these methods based on three themes of: nonsocial, antisocial, and prosocial behaviours. 

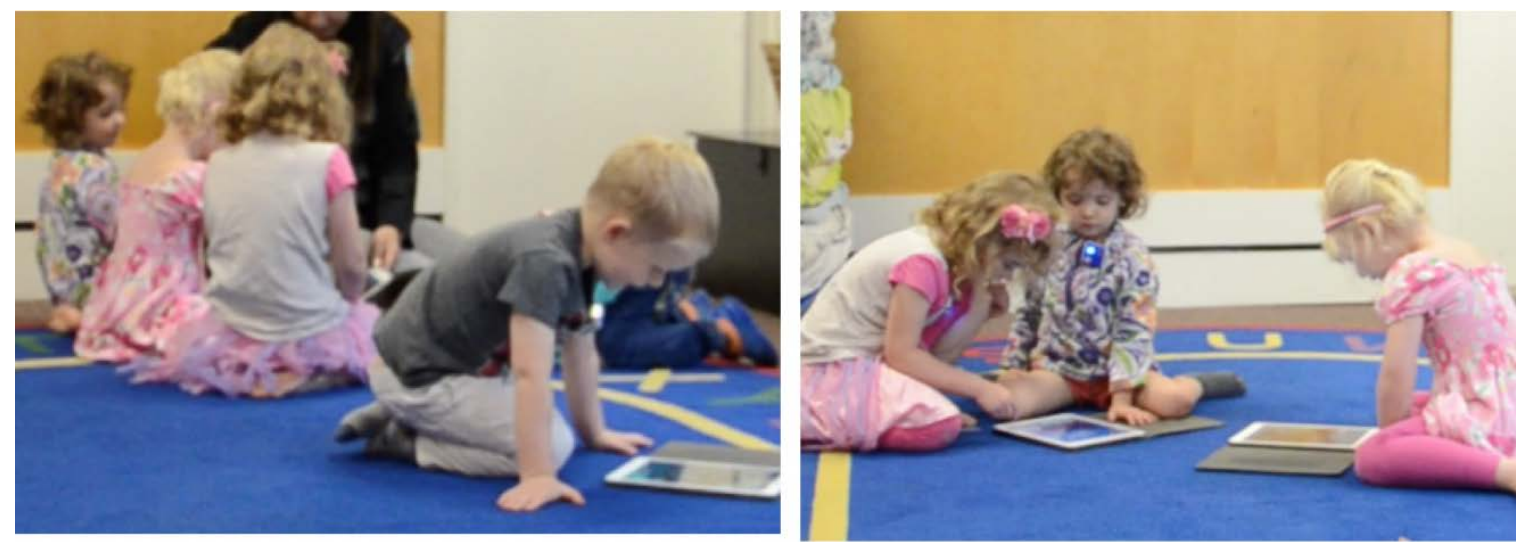

Figure 3. Participants 1 and 2 work independently while other participants work together.
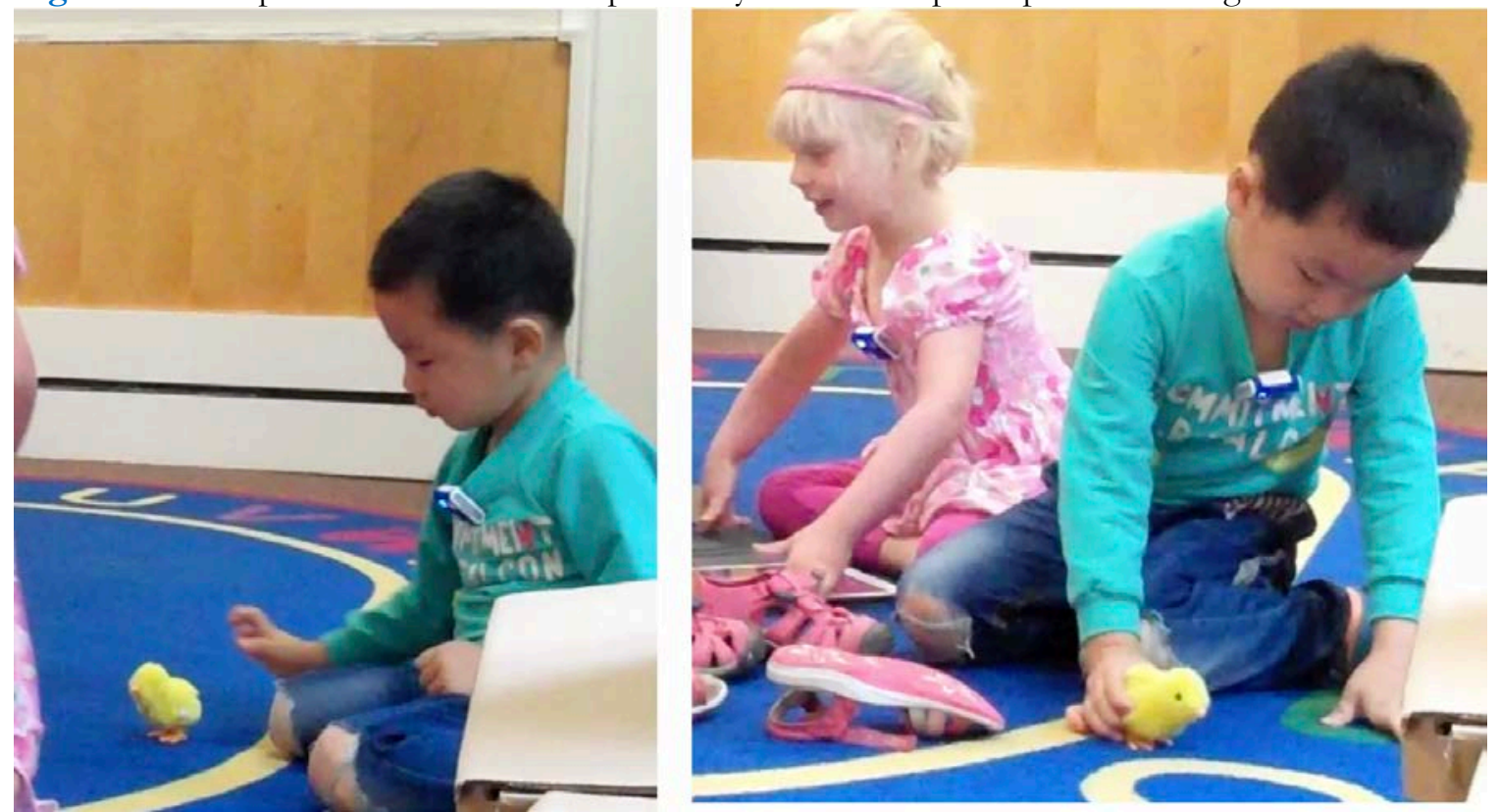

Figure 4. Participant 5 playing with other toys

\section{RESULTS}

The results of this study focus on the children using iPads independently from the researcher. The results are based on 206 observed behaviours and clustered into three main categories: nonsocial, antisocial, and prosocial. The following sections will describe the occurrences of these three behaviours.

\section{Nonsocial Observations}

Nonsocial behaviours occurred throughout the activity and were exhibited when the children worked independently (Figure 2). For the majority of time spent in the activity, the children interacted with each other, but at times they would work on their own. Nonsocial time occurred as there were five devices and three children. This did not allow for pairs or groups of three per device. Perhaps if there were fewer devices or more children, this situation would not occur. However, the number of devices was chosen based on prior research in the larger context of this study (Ralph, 2017b).

Sometimes children did not work with an iPad or with any other participants. They were distracted from the designated research activity and played with another toy (i.e., a chick) (Figure 3). They continued to work independently and were not involved in playing with devices. Participant 5 exhibited the most nonsocial behaviours, 8 (3.9\% of total behaviours). This may have to do with prior peer affiliations, as Participant 5 did not seem to know the other children as well as they knew each other.

\section{Antisocial Observations}

Antisocial behaviours observed were: pushing another's hand aside and pulling an item away (Figure 4). The children also displayed antisocial behaviours verbally. For example, Participant 3 pushed Participant 4's hand off 

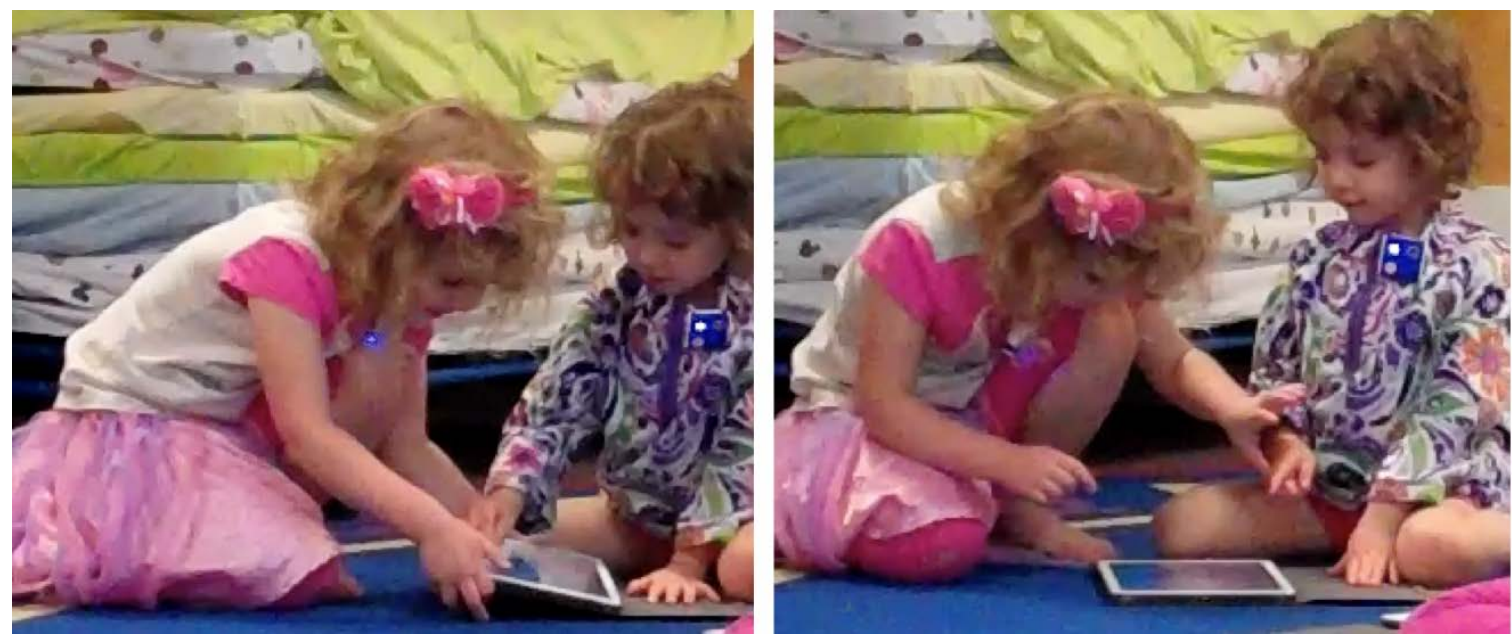

Figure 5. Participant 3 exhibiting antisocial behaviours.

the screen and said, "No, no, no. I want to do it. You do this!" Participant 4 said, "No!" in response. This lead to Participant 3 saying "No, no, no, no. No! I want to do it."

Other antisocial behaviours were verbally expressed using "I want." For example, Participants 1, 3, and 4 said, "I want to do it." When antisocial behaviours persisted, the researcher used verbal cues to encourage sharing, as reflective of a teacher in a classroom. For example, the researcher initiated prosocial behaviours for Participants 3 and 4 by reminding them to "take turns". Verbal cues initiated other prosocial sharing behaviours, such as touching the screen together. If the researcher did not intervene more persistent antisocial and perhaps even more aggressive behaviours would occur. However, as an interventionist methodology, DBR allows for researchers and teachers to act as they would in a traditional authentic classroom setting.

Their antisocial behaviours were not influenced by prior peer affiliations or who their friends were but by more reactionary aggression such as pushing or hitting (physical) or yelling (verbal) (Eisenberg-Berg, 1981; Eivers et al., 2012). Our study found that the children who pushed a hand away or said "no" or "I want" related to maintaining or obtaining control of the mobile device.

In another event of antisocial behaviours, Participant 2 took a picture of Participant 4 and proceeded to animate her photo in the app. He made her photo talk and made noises, such as, "Hootoo! Hootoo! Hootoo!" As the other children gathered around the iPad to laugh at Participant 2's funny animation, Participant 4 was becoming visually upset and began to cover her face and tears welled up in her eyes (Figure 5). Participants 2 and 3 exhibited the most antisocial behaviours, 3 (1.5\% of total behaviours).

The researcher noticed this right away and intervened by saying, "Wow you are a good model. Good picture," to Participant 4. The encouraging words from the researcher stopped the laughing and caused Participant 4 to smile. The researcher attempted to emulate the practice of the teacher, who would also intervene in this scenario. The behaviour of the children in this situation could have persisted to more bullying tactics or moved on to other victims. More longitudinal studies could identify these behaviours in the future. However, the least frequently observed behaviour was antisocial behaviour with only 9 events $(4.4 \%)$ and with only minor researcher intervention. The boys were two times (1\% of total behaviours) more antisocial and nonsocial than the girls.

Relational antisocial behaviour, such as making fun of someone to intentionally upset them (Liao et al., 2014; Renouf et al., 2010; Ronald et al., 2005; Sutton et al., 1999; Yagmurlu, 2014), only occurred once. The child understood what he was doing because he only targeted Participant 4, the smallest and youngest. However, when the researcher intervened and stopped the behaviour, it did not occur again. In this type of designed intervention research, targeted relational antisocial behaviour, bullying, or cyberbullying is likely reduced because researchers and teachers are present and can intervene in problematic negative behaviours, as is reflective of DBR methods (Brown, 1992; Jacobson, 2014). Even though these antisocial or aggressive incidents did occur, prosocial behaviours significantly outweighed the negative behaviours.

\section{Prosocial Observations}

Prosocial behaviours observed included: offering, allowing use, showing, watch together and participant controls, one participant holds while the other touches the screen, taking turns, multiple hands on the device, speaking together, and touching the screen together (Figure 6).

All five participants exhibited prosocial group behaviours 146 (70.9\% of total behaviours) (Figure 7). Participants 4 and 5 did not exhibit individual prosocial behaviours. Overall prosocial behaviours were the most common with 177 events (86\% of total behaviours). Individually, Participant 1 exhibited the most prosocial behaviours, 14 (6.8\% of total behaviours). For prosocial group measures, Participant 3 exhibited the most prosocial 


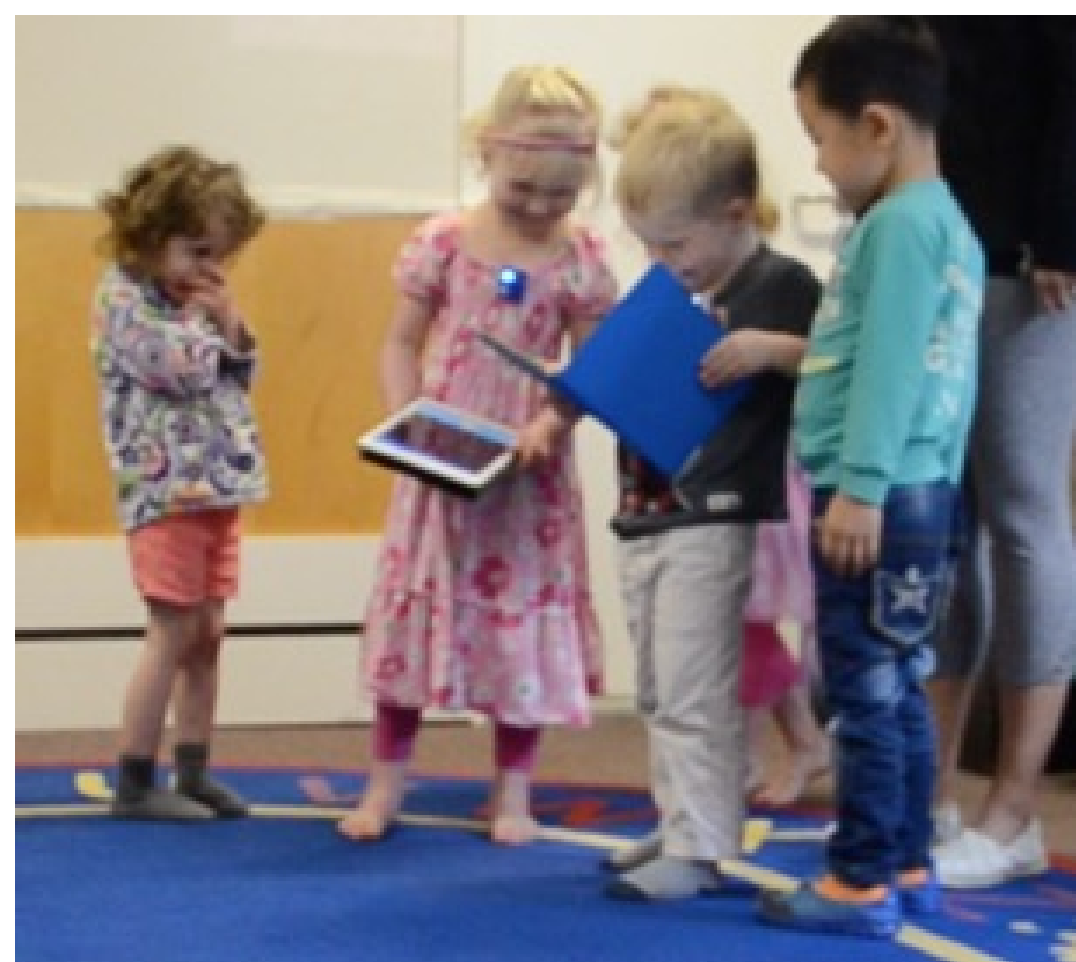

Figure 6. All participants laughing while Participant 4 covers her face

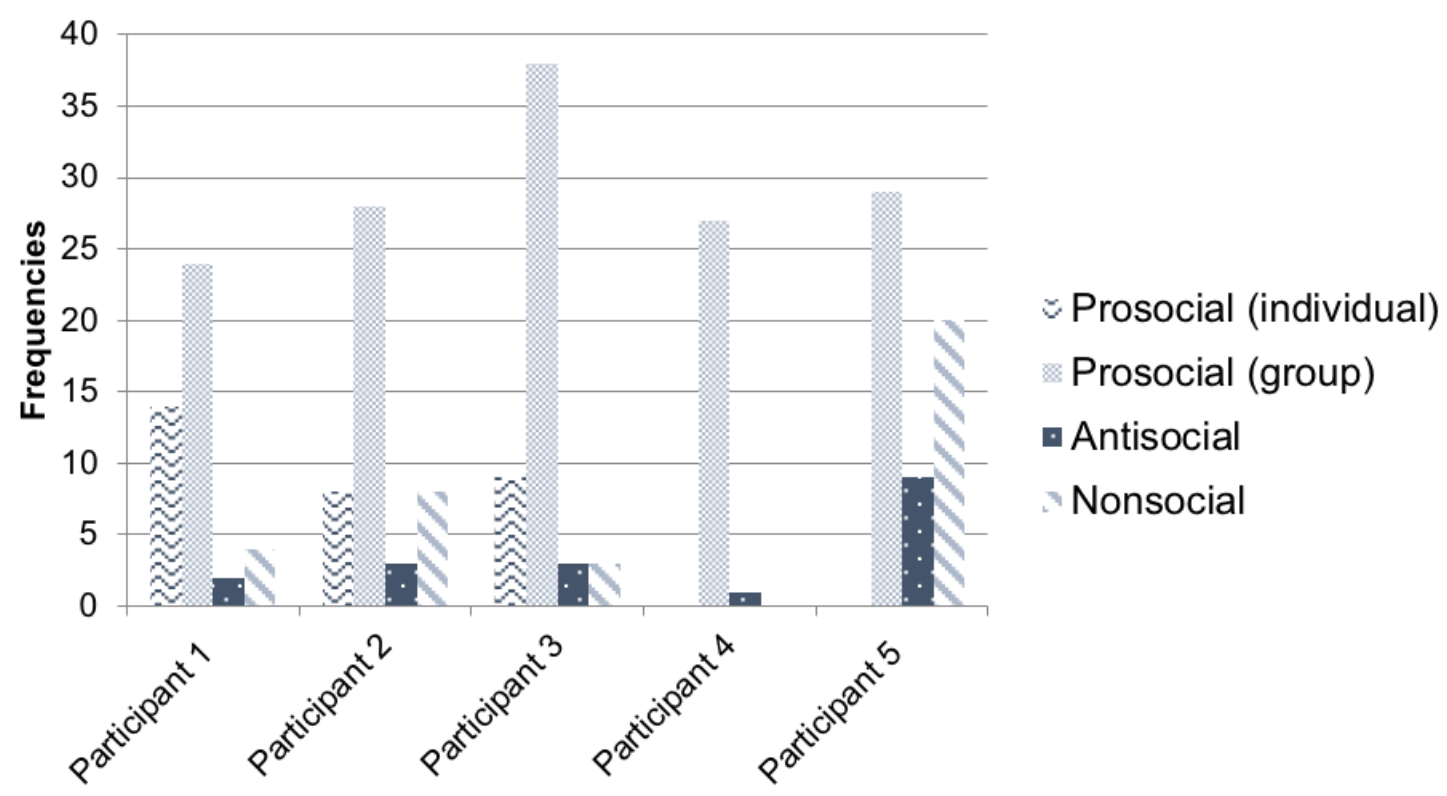

Figure 7. Participant (1-5) social behaviour counts with M\&T.

behaviours, 47 (22.8\% of total behaviours). On average, the boys exhibited slightly less prosocial behaviours than the girls with 30 to 37 events (15\% to $17 \%$ of total behaviours).

Figure 8 displays the individual prosocial sharing behaviours of showing, allowing use, and offering. Overall, showing was the most common sharing behaviour displayed, 20 (64.5\% of total behaviours). The least common individual behaviour was allowing use, 3 ( $9.7 \%$ of total behaviours). Participants 4 and 5 are removed from the figure as they did not display any individual sharing behaviours.

The children would gather around devices and watch the screen together after an animation was created. They would also sit on the floor together and touch the screen and speak into the device to record their voices together. The children would express the need to share and show their creations. Several times children said "look" and held up their device or pointed to the screen. Showing occurred more frequently when the children discovered the ability to add stickers to their screens. For example, Participant 1 said, "Look I got 2 butterflies."

This research supports other findings, as the children initially chose their groups based on prior relationships (Dahl et al., 2013; Fabes et al., 2012; Liao et al., 2014); however, the children in this study were seen to share with other children based on resource availability. There were three iPads and five children. The children shifted to 


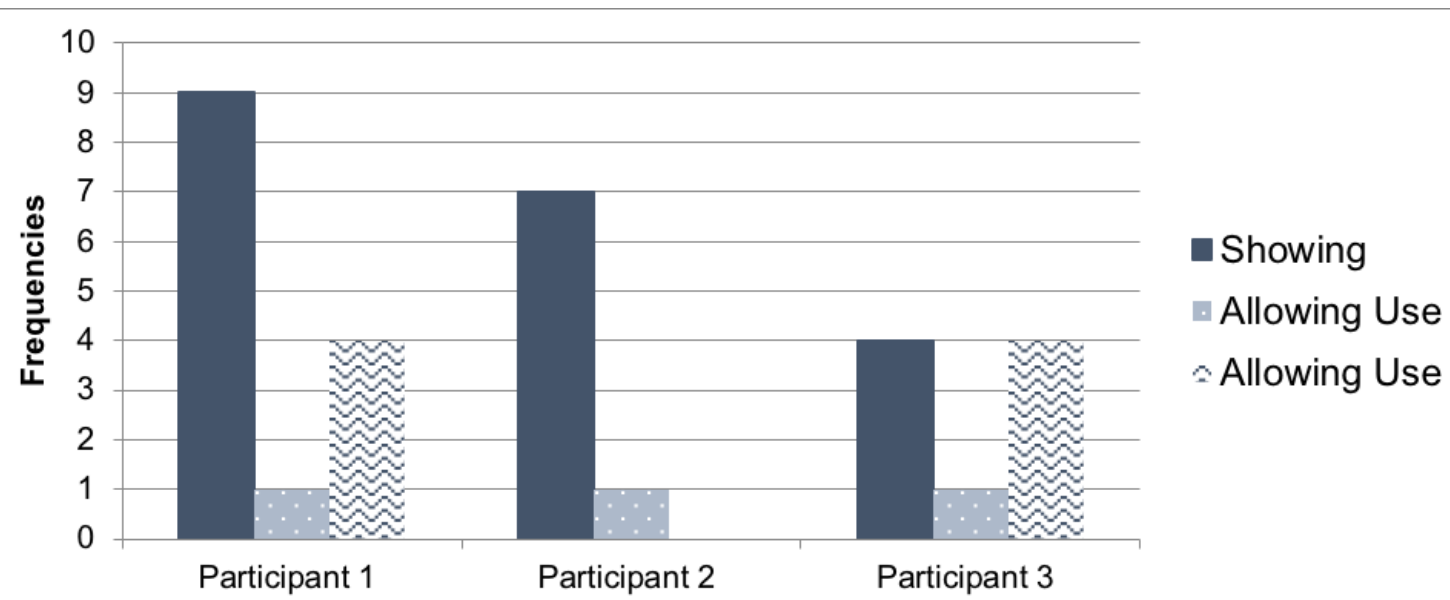

Figure 8. Individual prosocial behaviours per participant (1-3).

different groups based on who was in possession of the iPad and did not choose partners based on prior peer affiliations. In other words, the children clustered around who controlled the mobile device not just their friends.

This section described the results observed during this research, reflective of non, anti, and prosocial behaviours. The next section will discuss these results in more detail.

\section{DISCUSSION}

To reiterate, this research explored how preschool children's prosocial sharing behaviours progress or diminish when interacting with mobile devices. The themes that arose from this study include: videos for research with preschool-aged children and using mobile devices in ECE STEM education.

\section{Videos for Research with Preschool-aged Children}

As stated above, this study used video ethnographic methods to capture behaviours. Two cameras were used to reduce the partial representation that a video ethnographer captures (Hammersley and Atkinson, 2007). At times, the children moved out of shot and the researcher camera did not capture the behaviours (Figure 9). When the children moved out of the shot of the researcher camera, the Snapcam Ion continued to capture what the children were doing and was essential to data analysis (Figure 10).

At times, the point of view footage was dark or obscured when the children would lie down on the carpet or their shirt would cover the camera lens and some footage was lost. However, a significant amount of video was captured and supported the research camera. Even though there were times when the image was obscured, the cameras continuously captured the audio and the cameras acted as individual microphones. Some researchers recommend that children can capture their own footage in participatory research (Kullman, 2012); however, participatory research in which children use their own cameras is typically for children over six years old. This can extend research that encourages children to understand children's perspectives when using mobile devices (Dashti and Yateem, 2018). It allowed us an insight to the point of view of preschool-aged children. We can use these recordings to gain new knowledge to enhance our ethnographical understandings (Adams and Thompson, 2016). Wearable cameras with preschool-aged children are fairly unique in educational research and should be tested in other ECE settings.

Additionally, some of the children had speech difficulties, making it even more difficult to decipher what they were saying. When transcribing and coding, NVivo and video recordings were central to understand what was being said. Children would often speak at the same time, as is often the situation in preschools. If the voices were similar or unclear, watching the video footage allowed the researcher to look at the children's mouth and vocal gestures to see what words they were trying to say. Although some parents or research ethics boards may be hesitant about children being recorded, researchers need to emphasize the importance of capturing children's authentic behaviours on camera.

As mentioned earlier, video enables a "fine-grained scrutiny of moments of social life" (Heath et al., 2010, p. 3). This is very true for a preschool classroom. There are micro-moments that occurred and were captured. Whether children were saying it or moving around, we were able to capture the day to day, moment to moment experiences of these children. And we were also able to watch and rewatch the footage to get a better understanding of the occurrences. The ability to rewatch also allowed us to improve upon the OMPI measures (Ramaswamy and Bergin, 2009), which can be tested in future research. 

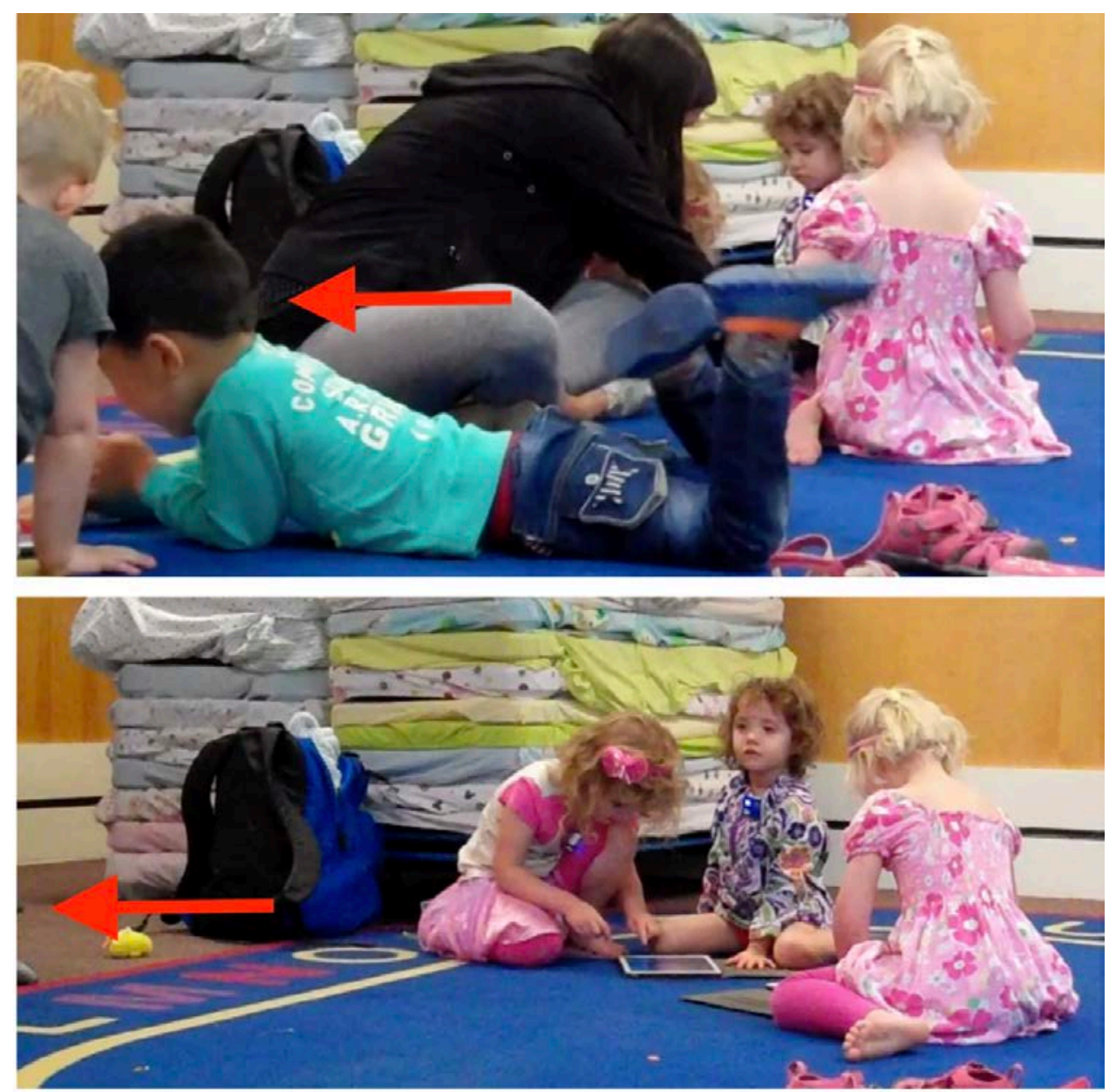

Figure 9. Participants 2 and 5 move out of researcher camera shot

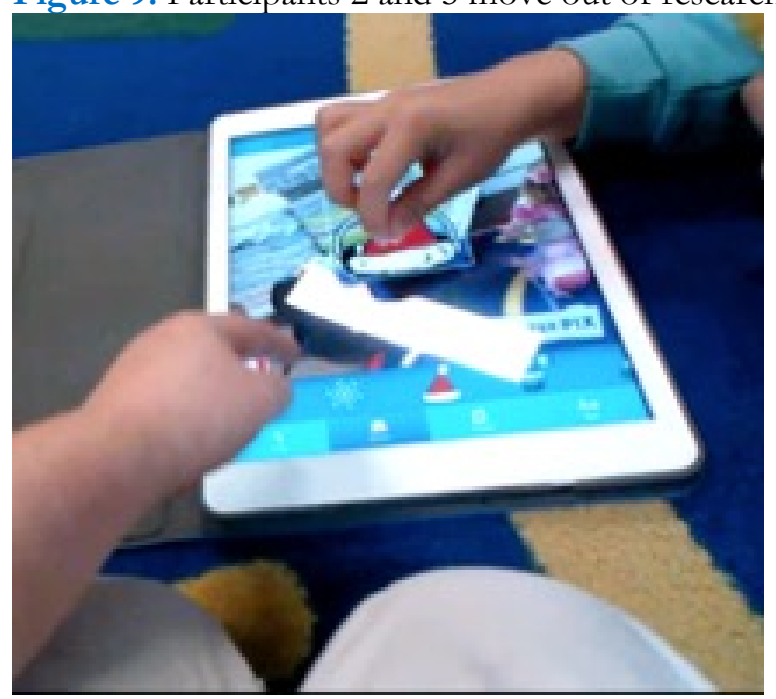

Figure 10. Participant 2's point of view camera

Using individual and other cameras in ECE is one way to include more technology into ECE STEM education. This research suggests more inclusion of mobile devices, which will be discussed in the following section.

\section{Using Mobile Devices in ECE STEM Education}

Using technology in ECE has been controversial and yet we are seeing an increase in use and systemic changes in policy. As research and policy suggest there are concerns for too much screen time, especially as many apps focus on drill and practice, which promotes low level and rote memorization style learning (American Academy of Pediatrics (AAP), 2014; Papadakis et al., 2018). Policy for preschool-aged children focuses on limitations of technology, while there is an increasing emphasis on STEM education and more devices in primary and secondary schools (Thibaut et al., 2018). These policies are slowly having an impact on STEM teacher education in postsecondary institutions (Ralph, 2016). 
If changes from kindergarten to grade 12 are occurring, changes in ECE should follow. Some changes in ECE have begun to occur based on the National Association for the Education of Young Children (NAEYC) and the Fred Rogers Center. They promote the use of interactive M\&T and interdisciplinary approaches like STEM to support the development of children and assist ECE teachers to support learning goals. Even the American Academy of Pediatrics (AAP)'s has changed its initial policy of banning and limiting devices to support the importance of M\&T to "allow children opportunities to discover and make choices... to explore, imagine and problem-solve" (American Academy of Pediatrics (AAP), 2016). Even with our small sample size, our research can inform these policies and STEM in ECE. In particular, our research uses STEM practices to promote social learning.

Social learning is a significant part of ECE, as preschool children are not only learning academic skills in these classrooms, but also social skills, including how to share and collaborate in STEM activities. Additional research is needed in the development of STEM literacies using devices, especially as more interactive apps are developed. In particular, Papadakis et al. (2018) suggest the challenges of designing appropriate interactive apps for children, as they need to be designed considering their developmental and cognitive abilities as well as content, including limited text. Even if an educator is informed and able to use the four pillar model or app rubric (Hirsh-Pasek et al., 2015; Papadakis et al., 2017), there are over 2.2 million apps and in particular over 300,000 for children (Apple, 2017). And as Papadakis et al. (2018) also suggest, there are no regulations on what defines an educational app. This is challenging to educators, policy makers, and researchers; however, this current research study and HirshPasek et al. (2015) alongside of Papadakis et al. (2017) can inform and assist in making these decisions.

This section discussed the results relating to video for research and mobile devices in preschool classrooms. The next section provides limitations, directions for future research, and a conclusion for this article.

\section{LIMITATIONS AND FUTURE RESEARCH}

The bias of this study was reduced through the triangulation of the qualitative and quantitative data. Also, to reduce bias, another coder contributed to inter-rater reliability. To reduce bias in the future, the researchers could invite the second coder to do the initial coding with the researcher as the second coder or apply a formal training process until inter-rater agreement is at least .8. A secondary limitation was the small sample size, which reduces generalizability or transferability. One reason for the small sample size was the use of video recordings. Some parents were not comfortable with their child being recorded and did not participate in the study. However, qualitative approaches tend to have smaller sample sizes, which allow for rich data. Also, sample size issues were reduced through the detailed coding which identified high frequencies of observed behaviours/events and multiple iterations until the intervention was deemed successful (over 200 observed behaviours). Small sample size concerns may not be an issue for those considering transferring the design or research findings to other settings that can include larger groups of children and more frequent iterations.

Another limitation was the time frame, as the results measured more short-term effects of the intervention. Due the limited scope of the school year, we do not know the long-term effects. For future research, ideally the intervention would be initiated at the beginning of the school year and continue throughout the year or following children through 2 years in a preschool program.

Implications for future research also include an extension to diverse ranges of ECE centres and a variety of new apps, as well as exploring other variables, and innovating with video ethnographic methods. First, the 'successful' intervention should be carried out in ECE centres in other settings, including rural settings in a range of different countries. In terms of other apps, research can explore the impact of more apps chosen based on the Hirsh-Pasek et al. (2015) four pillar model or on the Papadakis et al. (2018) rubric. Additionally, more research needs to be conducted in the development of digital literacy using tablet devices, especially as new and more interactive apps are developed.

The use of video ethnographic methods was imperative towards data collection and analysis. Although some Research Ethics Board representatives and parents may disprove of the use of wearable, point of view video with young children, the use of researcher and wearable cameras in this setting to capture moment-to-moment behaviours and interactions was imperative to interpreting linguistic and social situations. The Snapcam Ion cameras were essential for the data analysis as they captured individual perspectives, with close-up microphones and footage that may not be captured in a researcher camera's angle. This also can assist in exploring children's perspectives while using digital technologies (Dashti and Yateem, 2018). What does interaction with digital technologies mean to the children, from their point of view?

Finally, this type of research on prosocial behaviours should be conducted within differentiated preschool and ECE settings (e.g., Child Care, Head Start, High/Scope, Montessori, Reggio Emilia, and Waldorf). 


\section{CONCLUSION}

We need to ask what does interaction with M\&T mean to the children, from their point of view? What are the most relevant roles for M\&T in ECE (Petrina, Feng and Kim, 2008)? How do ECE teachers establish balance between experiential STEM activities and virtual activities, including virtual reality devices (Ralph, 2017b)? This research focused on prosocial behaviours, with an intention of informing educational and familial decisions on children's access to and interactions with M\&T. Using DBR, the specific intent was to test interventions that inform the design of activities and apps that facilitate children's prosocial behaviour. In addition to employing devices for an expansion of children's STEM literacies, a challenge is developing scenarios that forefront prosocial behaviours and sharing.

\section{REFERENCES}

Adams, C. and Thompson, T. L. (2016). Researching a posthuman world: Interviews with digital objects. London, UK: Palgrave Macmillan. https:// doi.org/10.1057/978-1-137-57162-5

American Academy of Pediatrics (AAP). (2014). The benefits of limiting TV. Available at: http://www.healthychildren.org/English/family-life/Media/Pages/The-Benefits-of-Limiting-TV.aspx

(Accessed 15 October 2014)

American Academy of Pediatrics (AAP). (2016). American Academy of Pediatrics announces new recommendations for children's media use. Available at: https://www.aap.org/en-us/about-the-aap/aappress-room/Pages/American-Academy-of-Pediatrics-Announces-New-Recommendations-for-ChildrensMedia-Use.aspx (Accessed 26 October 2016)

Anderson, T. and Shattuck, J. (2012). Design-based research: A decade of progress in education research? Educational Researcher, 41(1), 16-25. https://doi.org/10.3102/0013189X11428813

Apple. (2017). App Store shatters records on New Year's Day. Available at: http://www.apple.com/newsroom/2017/01/app-store-shatters-records-on-new-years-day.html (Accessed 23 March 2017)

Bandura, A. (1977). Social learning theory. Englewood Cliffs, N.J.: Prentice Hall.

Barab, S. and Squire, K. (2004). Design-based research: Putting a stake in the ground. Journal of the Learning Sciences, 13(1), 1-14. https://doi.org/10.1207/s15327809j1s1301_1

Belacchi, C. and Farina, E. (2012). Feeling and thinking of others: Affective and cognitive empathy and emotion comprehension in prosocial/hostile preschoolers. Aggressive Behavior, 38(2), 150-165. https://doi.org/10.1002/ab.21415

Berkowitz, A. D. (2004). The social norms approach: Theory, research, and annotated bibliography. Available at: http://www.edc.org/hec/socialnorms/theory.html (Accessed 14 September 2016)

Bierhoff, H.-W. (2002). Prosocial behaviour. New York, NY: Psychology Press.

Brown, A. L. (1992). Design experiments: Theoretical and methodological challenges in creating complex interventions in classroom settings. Journal of the Learning Sciences, 2(22), 141-178. https://doi.org/10.1207/s15327809j1s0202_2

Brownell, C. A., Svetlova, M., Anderson, R., Nichols, S. R. and Drummond, J. (2013). Socialization of early prosocial behavior: Parents' talk about emotions is associated with sharing and helping in toddlers. Infancy, 18(1), 91-119. https://doi.org/10.1111/j.1532-7078.2012.00125.x

Bullock, E. P., Shumway, J. F., Watts, C. M. and Moyer-Packenham, P. S. (2017). Affordance access matters: Preschool children's learning progressions while interacting with touch-screen mathematics apps. Technology, Knowledge and Learning, 22(3), 485-511. https:/ / doi.org/10.1007/s10758-017-9312-5

Chang, J.-H., Chiu, P.-S. and Huang, Y.-M. (2018). A sharing mind map-oriented approach to enhance collaborative mobile learning with eigital archiving systems. International Review of Research in Open and Distributed Learning, 19(1), 1-24. https:// doi.org/10.19173/irrodl.v19i1.3168

Chernyak, N. and Kushnir, T. (2013). Giving preschoolers choice increases sharing behavior. Psychological Science, 24(10), 1971-1979. https:// doi.org/10.1177/0956797613482335

Clayton, R. B., Osborne, R. E., Miller, B. K. and Oberle, C. D. (2013). Loneliness, anxiousness, and substance use as predictors of Facebook use. Computers in Human Bebavior, 29(3), 687-693. https://doi.org/10.1016/j.chb.2012.12.002

Collins, A., Joseph, D. and Bielaczyc, K. (2004). Design research: Theoretical and methodological issues. Journal of the Learning Sciences, 13(1), 15-42. https://doi.org/10.1207/s15327809j1s1301_2

Creswell, J. W. (2013). Qualitative inquiry and research design: Choosing among five approaches. Los Angeles, CA: SAGE Publications. 
Dahl, A., Schuck, R. K. and Campos, J. J. (2013). Do young toddlers act on their social preferences? Developmental Psychology, 49(10), 1964-1970. https://doi.org/10.1037/a0031460

Dashti, F. A. and Yateem, A. K. (2018). Use of mobile devices: A case study with children from Kuwait and the United States. International Journal of Early Childhood, 50(1), 121-134. https:// doi.org/10.1007/s13158-018-0208$\mathrm{X}$

De Simone, J. J. (2013). What is good can also be bad: The prosocial and antisocial in-game behaviors of young video game players. Atlantic Journal of Communication, 21(3), 149-163. https://doi.org/10.1080/15456870.2013.801756

Dede, C. (2005). Why design-based research is both important and difficult. Educational Technology, 45(1), 13-17.

Design-Based Research Collective. (2003). Design based research: An emerging paradigm for educational inquiry. Educational Researcher, 32(1), 5-8. https:// doi.org/10.3102/0013189X032001005

Dockett, S., Einarsdottir, J. and Perry, B. (2009). Researching with children: Ethical tensions. Journal of Early Childhood Research, 7(3), 283-298. https://doi.org/10.1177/1476718X09336971

Dunfield, K. A. (2014). A construct divided: prosocial behavior as helping, sharing, and comforting subtypes. Frontiers in Psychology, 5. https:/ / doi.org/10.3389/fpsyg.2014.00958

Edelson, D. C. (2002). Design research: What we learn when we engage in design. Journal of the Learning Sciences, 11(1), 105-121. https://doi.org/10.1207/S15327809JLS1101_4

Edwards, C. and Pye, A. (2011). For and against social networking technology. Engineering \& Technology, 6(9), 28 29. https://doi.org/10.1049/et.2011.0900

Eisenberg, N. (1982). The development of prosocial behavior. New York, NY: Academic Press.

Eisenberg, N., Hofer, C., Sulik, M. J. and Liew, J. (2014). The development of prosocial moral reasoning and a prosocial orientation in young adulthood: Concurrent and longitudinal correlates. Developmental Psychology, 50(1), 58-70. https://doi.org/10.1037/a0032990

Eisenberg-Berg, N. (1981). Relationship of preschool children's habitual use of space to prosocial, antisocial, and social behaviors. Journal of Genetic Psychology, 138, 111-121. https://doi.org/10.1080/00221325.1981.10532848

Eivers, A. R., Brendgen, M., Vitaro, F. f. and Borge, A. I. H. (2012). Concurrent and longitudinal links between children's and their friends' antisocial and prosocial behavior in preschool. Early Childhood Research Quarterly, 27(1), 137-146. https:// doi.org/10.1016/j.ecresq.2011.05.001

Erickson, F. (2011). Uses of video in social research: A brief history. International Journal of Social Research Methodology, 14(3), 179-189.

Erickson, F. and Wilson, J. (1982). Sights and sounds of life in schools: A resource guide to film and videotape for research and education. East Lansing, MI: Michigan State University, Institute for Research on Teaching of the College of Education.

Fabes, R. A., Hanish, L. D., Martin, C. L., Moss, A. and Reesing, A. (2012). The effects of young children's affiliations with prosocial peers on subsequent emotionality in peer interactions. British Journal of Developmental Psychology, 30(4), 569-585. https://doi.org/10.1111/j.2044-835X.2011.02073.x

Feldman, R., Bamberger, E. and Kanat-Maymon, Y. (2013). Parent-specific reciprocity from infancy to adolescence shapes children's social competence and dialogical skills. Attachment \& Human Development, 15(4), 407-423. https://doi.org/10.1080/14616734.2013.782650

Fetterman, D. M. (1989). Ethnography: Step by step. Newbury Park, CA: Sage.

Flewitt, R., Messer, D. and Kucirkova, N. (2014). New directions for early literacy in a digital age: The iPad. Journal of Early Childhood Literacy, 15(4), 1-22.

Fujisawa, K. K., Kutsukake, N. and Hasegawa, T. (2008). Reciprocity of prosocial behavior in Japanese preschool children. International Journal of Behavioral Development, 32(2), 89-97. https://doi.org/10.1177/0165025407084055

Graham, A., Powell, M., Taylor, N., Anderson, D. and Fitzgerald, R. (2013). Ethical research involving children. Florence, Italy: UNICEF Office of Research - Innocenti.

Hammersley, M. and Atkinson, P. (2007). Ethnography: Principles in practice (3rd ed.). New York: Routledge. https://doi.org/10.1002/9781405165518.wbeose070

Hay, D. F., Castle, J., Davies, L., Demetriou, H. and Stimson, C. A. (1999). Prosocial action in very early childhood. Journal of Child Psychology and Psychiatry, 40(6), 905-916. https://doi.org/10.1111/1469-7610.00508

Hayashi, A. and Tobin, J. (2012). Reframing a visual ethnography of a Japanese preschool classroom. Visual Anthropology Review, 28(1), 13-31. https:// doi.org/10.1111/j.1548-7458.2012.01108.x

Heath, C., Hindmarsh, J. and Luff, P. (2010). Video in qualitative research: Analysing social interaction in everyday life. London, UK: Sage Publications. https://doi.org/10.4135/9781526435385

Herodotou, C. (2018). Mobile games and science learning: A comparative study of 4 and 5 years old playing the game Angry Birds. British Journal of Educational Technology, 49(1), 6-16. https://doi.org/10.1111/bjet.12546 
Hirsh-Pasek, K., Zosh, J. M., Golinkoff, R. M., Gray, J. H., Robb, M. B. and Kaufman, J. (2015). Putting education in "educational" apps lessons from the science of learning. Psychological Science in the Public Interest, 16(1), 3-34. https://doi.org/10.1177/1529100615569721

Hunleth, J. (2011). Beyond on or with: Questioning power dynamics and knowledge production in 'child-oriented' research methodology. Childhood, 18(1), 81-89. https:// doi.org/10.1177/0907568210371234

IBM Corp. (2016). IBM SPSS Statistics for Mac, Version 24. Armonk, NY: IBM Corp.

Jacobson, M. (2014). Design-based research: Sponsoring innovation in education. Education Canada, 54(5), 22-24.

Kullman, K. (2012). Experiments with moving children and digital cameras. Children's Geographies, 10(1), 1-16. https://doi.org/10.1080/14733285.2011.638174

Liao, Z., Li, Y. and Su, Y. (2014). Emotion understanding and reconciliation in overt and relational conflict scenarios among preschoolers. International Journal of Behavioral Development, 38(2), 111-117. https://doi.org/10.1177/0165025413512064

Luzón, M. J. (2011). 'Interesting post, but I disagree': Social presence and antisocial behaviour in academic weblogs. Applied Linguistics, 32(5), 517-540. https://doi.org/10.1093/applin/amr021

Lynch, J. and Redpath, T. (2014). 'Smart' technologies in early years literacy education: A metanarrative of paradigmatic tensions in iPad use in an Australian preparatory classroom. Journal of Early Childhood Literacy, 14(2), 147-174. https://doi.org/10.1177/1468798412453150

Mascheroni, G. and Ólafsson, K. (2014). Net children go mobile: risks and opportunities (2nd ed.). Milan, Italy: Educatt.

Medvin, M. B., Spargo, B. and Falcocchio, A. (2000). Using computers to facilitate social problem solving in head start classrooms. Paper presented at the Paper presented at the Head Start National Research Conference, Washington, DC.

Muller, A. A. and Perlmutter, M. (1984). Preschool children's problem-solving interactions at computers and jigsaw puzzles. Journal of Applied Developmental Psychology, 6, 173-186. https:/ / doi.org/10.1016/0193-3973(85)90058-9

Musante, K. (2014). Participant observation. In H. R. Bernard \& C. C. Gravlee (Eds.), Handbook of methods in cultural anthropology. USA: Rowman \& Littlefield Publishers.

Pallant, J. (2010). SPSS survivial manual: A step by step guide to data analysis using SPSS (4th ed.). New York, NY: Allen \& Unwin Book Publishers.

Papadakis, S., Kalogiannakis, M. and Zaranis, N. (2017). Designing and creating an educational app rubric for preschool teachers. Education and Information Technologies, 22(6), 3147-3165. https://doi.org/10.1007/s10639017-9579-0

Papadakis, S., Kalogiannakis, M. and Zaranis, N. (2018). Educational apps from the Android Google Play for Greek preschoolers: A systematic review. Computers \& Education, 116, 139-160. https://doi.org/10.1016/j.compedu.2017.09.007

Paulus, M. and Moore, C. (2014). The development of recipient-dependent sharing behavior and sharing expectations in preschool children. Developmental Psychology, 50(3), 914-921. https://doi.org/10.1037/a0034169

Paulus, M., Gillis, S., Li, J. and Moore, C. (2013). Preschool children involve a third party in a dyadic sharing situation based on fairness. Journal of Experimental Child Psychology, 116(1), 78-85. https://doi.org/10.1016/j.jecp.2012.12.014

Pearce, C., Arnold, M., Phillips, C. and Dwan, K. (2010). Methodological considerations of digital video observation: Beyond conversation analysis. International Journal of Multiple Research Approaches, 4(2), 90-99. https://doi.org/10.5172/mra.2010.4.2.090

Persson, G. E. B. (2005). Developmental perspectives on prosocial and aggressive motives in preschoolers' peer interactions. International Journal of Behavioral Development, 29(1), 80-91. https://doi.org/10.1080/01650250444000423

Petrina, S., Feng, F. and Kim, J. (2008). Researching cognition and technology: How we learn across the lifespan. International Journal of Technology \& Design Education, 18(4), 375-396. https:// doi.org/10.1007/s10798-007-90335

Plowman, L., McPake, J. and Stephen, C. (2008). Just picking it up? Young children learning with technology at home. Cambridge Journal of Education, 38(3), 303-319. https:// doi.org/10.1080/03057640802287564

QSR International. (2016). NVivo qualitative data analysis Software, Version 11: QSR International Pty Ltd.

Radke-Yarrow, M., Zahn-Waxler, C., Barrett, D., Darby, J., King, R., Pickett, M. and Smith, J. (1976). Dimensions and correlates of prosocial behavior in young children. Child Development, 47(1), 118-125. https://doi.org/10.2307/1128290

Ralph, R. (2016). Post secondary project-based learning in science, technology, engineering and mathematics. Journal of Technology and Science Education, 6(1), 26-35. https://doi.org/10.3926/jotse.155

Ralph, R. (2017a). How to choose an 'educational' app: Making the pedagogical choice. Canadian Teacher, 3, 28-29.

Ralph, R. (2017b). Sharing is caring: Prosocial behaviours, theory of mind, and media and technology in early childhood education. Unpublished doctoral dissertation. University of British Columbia. Vancouver, BC. 
Ramaswamy, V. and Bergin, C. (2009). Do reinforcement and induction increase prosocial behavior? Results of a teacher-based intervention in preschools. Journal of Research in Childhood Education, 23(4), 527-538. https://doi.org/10.1080/02568540909594679

Reimann, P. (2011). Chapter 3 design-based research. In M. L., P. Freebody and J. Irwin (Eds.), Methodological choice and design. New York, NY: Springer Science and Business Media.

Renouf, A., Brendgen, M., Parent, S., Vitaro, F., Zelazo, P. D., Boivin, M., . . Seguin, J. R. (2010). Relations between theory of mind and indirect and physical aggression in kindergarten: Evidence of the moderating role of prosocial behaviors. Social Development, 19(3), 535-555. https://doi.org/10.1111/j.1467-9507.2009.00552.x

Ronald, A., Happé, F., Hughes, C. and Plomin, R. (2005). Nice and nasty theory of mind in preschool children: Nature and nurture. Social Development, 14(4), 664-684. https://doi.org/10.1111/j.1467-9507.2005.00323.x

Rosen, L. D., Whaling, K., Rab, S., Carrier, L. M. and Cheever, N. A. (2013). Is Facebook creating "iDisorders"? The link between clinical symptoms of psychiatric disorders and technology use, attitudes and anxiety. Computers in Human Behavior, 29(3), 1243-1254. https:/ / doi.org/10.1016/j.chb.2012.11.012

Sandoval, W. A. and Bell, P. (2004). Design-based research methods for studying learning in context: Introduction. Educational Psychologist, 39(4), 199-201. https://doi.org/10.1207/s15326985ep3904_1

Sutton, J., Smith, P. K. and Swettenham, J. (1999). Bullying and 'theory of mind': A critique of the 'social skills deficit' view of anti-social behaviour. Social Development, 8(1), 117-127. https://doi.org/10.1111/14679507.00083

Thibaut, L., Ceuppens, S., De Loof, H., De Meester, J., Goovaerts, L., Struyf, A., . . Depaepe, F. (2018). Integrated STEM education: A systematic review of instructional practices in secondary education. European Journal of STEM Education, 3(1). https://doi.org/10.20897/ejsteme/85525

Vygotsky, L. S. (1978). Mind in society: The development of higher psychological processes (M. Cole, V. John-Stiener, S. Scribner and E. Souberman Eds.). Cambridge, MA: Harvard University Press.

Wang, F. and Hannafin, M. J. (2005). Design-based research and technology-enhanced learning environments. Educational Technology Research and Development, 53(4), 5-23. https://doi.org/10.1007/BF02504682

Warneken, F. and Tomasello, M. (2013). The emergence of contingent reciprocity in young children. Journal of Experimental Child Psychology, 116(2), 338-350. https://doi.org/10.1016/j.jecp.2013.06.002

Yagmurlu, B. (2014). Relations among sociocognitive abilities and prosocial behavior. Journal of Child and Family Studies, 23(3), 591-603. https://doi.org/10.1007/s10826-013-9726-1

Zhou, N. and Yadav, A. (2017). Effects of multimedia story reading and questioning on preschoolers' vocabulary learning, story comprehension and reading engagement. Educational Technology Research and Development, 65(6), 1523-1545. https://doi.org/10.1007/s11423-017-9533-2

Zimmerman, B. J. (2002). Becoming a self-regulated learner: An overview. Theory into Practice, 41(2), 64-70. https://doi.org/10.1207/s15430421 tip4102_2 